\title{
Analysis of Influencing Factors of Micro-blog Marketing Effect
}

\author{
Xin Yong-rong \\ Jiangsu Open University \\ Nanjing, China \\ E-mail xinyongrong@126.com
}

\author{
Huang Qing-ping \\ Jiangsu Open University \\ Nanjing, China \\ E-mail 2906871012@qq.com
}

\author{
Zuo Xiu-ping \\ Jiangsu Open University \\ Nanjing, China \\ E-mail zxp20031014@163.com
}

\begin{abstract}
- this paper firstly establishes the evaluation index system of micro-blog and micro-blog information evaluation index system of marketing effect by analyzing the structural features of micro-blog information, and analyzes information quality, credibility, micro-blog micro-blog micro-blog marketing interactive and brand exposure impact on micro-blog's marketing effect, which is based on 9 assumptions of their relationship and establish a structural equation model, using 12 skincare brand micro-blog account of cosmetics industry in January 2017 to verify the hypotheses are June week data. The results show that: the quality of information, micro-blog brand exposure, micro-blog interactive and micro-blog credibility have different degrees of impact on the micro-blog marketing effect, 8 hypotheses through the test of significance in different degree, but the path coefficient is generally low. So enterprises should pay further attention in establishment and maintenance of microblog marketing brand credibility, release high quality information and enhance enterprise brand visibility, so as to realize the integration of the microblog marketing effect.
\end{abstract}

Keywords-Microblog information; Microblog marketing; Structural equation model

\section{INTRODUCTION}

With the rapid development of network in our country, the new type of social media have sprung up in succession, the emotional expression and communication of people in the event of a rapid change, especially the application of web2.0, various forms of communication tool is gradually changing the transmission channels and means of social information. Microblog has become the current user's fastest-growing interpersonal interaction pattern with its characteristics of concise, immediacy, open new, interactive, interesting, autonomy and cross-platform features,

Twitter has a wide range of the fan, including fortune 500 companies as early as in 2006 shortly after the blog technology pioneer Evan Williams launched it. In China, Microblog got the fission development after it born later than abroad four to five years, but it is from birth to promote in just more than a year. Microblog became the most important social media for the enterprise marketing in 2012. And microblog marketing has become a mainstream way of social media marketing. Therefore it is a focus to the many enterprises how to carry out the network marketing in microblog user group of 540 million. The premise is to find out the effect factors having important influence on microblog marketing, and targeted to carry out microblog marketing.

\section{RELATED RESEARCH REVIEWED}

It can search a total of 1929 academic theses on the title of "microblog marketing" from the existing literature on June 30, 2017 through Chinese full-text periodicals network. These theses analyzes mainly based on the characteristics and modes of microblog marketing, driving factors, value, operation mode, the effect evaluation, marketing strategy and the challenge. Comprehensive is known, literature research on microblog marketing effect factors does not see more, scholars focus more on the associated with the microblog marketing strategy analysis.

Sun Jianghua probes into the strategies and tactics of the microblog marketing by analysing search, and labels, three factors influence on microblog marketing; Wang Xiaoguang fang found that microblog marketing has an important influence on network platform spread of public discourse by analyzing sina microblog marketing; But Lin Daiying found that information is easy to fade by studying information, and put forward that the enterprises should grasp the aging law of information on microblog marketing, improve information preservation by marketing events or fan interaction ability, improve enterprise microblog marketing effect.

In empirical study, Jin Kun found that the opinion leaders effect on the sensitive information spread is greater than the sensitive information dissemination effect, has a very good reference value to microblog marketing path designing ;

Liu Tong built short-term interaction model on 10 case data of the sina microblog microblog marketing based on the 
AISAS model, and the results showed that the microblog number, the number of fans is proportional to the microblog marketing influence, well-known brands have first-mover advantage in microblog marketing, but microblog marketing effect will be weak as time goes on, so should keep enterprise microblog activity;

Huang Quipping found that enterprises should pay attention to the interaction when implement microblog marketing communication, timeliness and simplify, etc., by establishing the TAM and the IDT model to analyzes the microblog marketing attitude and willingness to key variables.

To sum up, research on microblog marketing effect factors is limited, and stay on the qualitative analysis due to the development of microblog in China no more than five years. Therefore, it has important guiding significance to enterprises to do further research on microblog marketing factors, especially the characteristic of information elaboration on microblog marketing. It is advantageous to the enterprise better play microblog marketing "butterfly effect", realize the enterprise brand value appreciation, and at the same time avoid the influence of the "negative effect" to the enterprise brand.

\section{SYSTEM BUILDING AND RESEARCH HYPOTHESIS}

\section{A. Construction to index system of microblog marketing influencing factors}

Microblog users will pay a spontaneous attention and forwarding due to the microblog information features, this is the dominant microblog attractive. In addition, the microblog users can attract potential users subconsciously through active marketing way, so to be concerned, forwarded and even interaction, this is hidden attraction. Microblog comprehensive literature study shows that related influencing factors mainly include microblog credibility, enterprises and the state of interaction between the fan and brand activities, such as microblog activity. Index involved in and evaluation results as shown in table 1.

TABLE I. MICROBLOG MARKETING EVALUATION INDEX SYSTEM OF INFLUENCING FACTORS AND INSPECTION RESULTS OF MEASUREMENT EQUATION

\begin{tabular}{|c|c|c|c|c|c|c|}
\hline Latent variables & Symbol & Indicators & Symbol & The value & $\begin{array}{c}\text { Factor } \\
\text { loading }\end{array}$ & $\begin{array}{l}\text { T test } \\
\text { Value }^{1}\end{array}$ \\
\hline \multirow{4}{*}{ Brand visibility } & \multirow{4}{*}{ Y1 } & $\begin{array}{l}\text { Brand name } \\
\text { occurrences }\end{array}$ & $y_{11}$ & $\begin{array}{c}\text { According to the number of brands in the microblog information } \\
\text { statistics }\end{array}$ & 0.78 & $7.54^{* * *}$ \\
\hline & & Number of fans & $y_{12}$ & fans Paying attention to the microblog & 0.91 & $10.85^{* * *}$ \\
\hline & & $\begin{array}{c}\text { Microblog } \\
\text { information quantity }\end{array}$ & $y_{13}$ & The total number of microblog released information & 0.95 & $22.37 * * *$ \\
\hline & & Forward speed & $y_{14}$ & According to the forward speed assignment 1 to 5 in turn & 0.89 & $8.78^{* * *}$ \\
\hline \multirow{4}{*}{ Interactivity } & \multirow{4}{*}{$\mathrm{Y} 2$} & $\begin{array}{l}\text { Amount of } \\
\text { forwarding }\end{array}$ & $y_{21}$ & Number of microblog message forwarding & 0.99 & $8.29 * * *$ \\
\hline & & Amount of comment & $y_{22}$ & number of microblog information comments & 0.92 & $12.11^{* * *}$ \\
\hline & & Amount of activities & $y_{23}$ & The number of fans to participate in business activities & 0.88 & $23.75^{* * *}$ \\
\hline & & Enterprise replies & $y_{24}$ & Enterprise replies to fan comments & 0.95 & $11.79 * * *$ \\
\hline \multirow{3}{*}{ Conversion rate } & \multirow{3}{*}{ Y3 } & $\begin{array}{l}\text { The number of } \\
\text { registered users }\end{array}$ & $y_{31}$ & The number of registered users link home page & 0.87 & $9.54 * * *$ \\
\hline & & $\begin{array}{c}\text { Coupon application } \\
\text { number }\end{array}$ & $y_{32}$ & application number of coupons enterprise issued & 0.84 & $8.21^{* * *}$ \\
\hline & & The online order & $y_{33}$ & number of the buyer consultation and the product & 0.97 & $18.76^{* * *}$ \\
\hline \multirow{5}{*}{$\begin{array}{c}\text { Microblog } \\
\text { information quality }\end{array}$} & \multirow{5}{*}{$\mathrm{X} 1$} & Information number & $x_{11}$ & Statistics of the number of characters each post information & 0.84 & $14.51 * * *$ \\
\hline & & Original information & $x_{12}$ & Is assigned a value of 1 , no assignment 0 & 0.93 & $9.73^{* * *}$ \\
\hline & & $\begin{array}{l}\text { Interesting } \\
\text { information }\end{array}$ & $x_{13}$ & According to their interest in assignment 1 to 5 & 0.95 & $9.88^{* * *}$ \\
\hline & & Information types & $x_{14}$ & $\begin{array}{l}\text { Words assignment } 1 \text {, pictures assignment } 2 \text {, video assignment } 3 \text {, } \\
\text { words and pictures, and video, mixed assignment } 4,5 \text {, } \\
\text { respectively. }\end{array}$ & 0.89 & $12.37 * * *$ \\
\hline & & Whether advertising & $x_{15}$ & Is 1 , otherwise 0 . & 0.92 & 8.54 \\
\hline \multirow{3}{*}{$\begin{array}{l}\text { Microblog } \\
\text { credibility }\end{array}$} & \multirow{3}{*}{$\mathrm{X}_{2}$} & Certification or not & $x_{21}$ & Has passed the certification of assignment 1 , otherwise 0. & 0.86 & 9.95 \\
\hline & & $\begin{array}{l}\text { Amount of opinion } \\
\text { leaders }\end{array}$ & $x_{22}$ & The number of celebrities in the microblog fans. & 0.88 & 13.05 \\
\hline & & public praise & $x_{23}$ & $\begin{array}{l}\text { According to the word of mouth good or bad, in turn, the } \\
\text { assignment } 1 \text { to } 5 \text {. }\end{array}$ & 0.95 & 15.74 \\
\hline
\end{tabular}

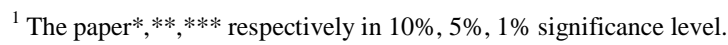




\section{B. Relationship analysis and the research hypothesis}

In order to determine microblog marketing direct and indirect effect relationship between influence factors puts forward the following hypothesis, and established the theory of structural equation.

$\mathrm{H} 1$ :Brand visibility has a positive role in promoting microblog marketing interaction $\left(Y_{1} \rightarrow Y_{2}\right)$

H2: Brand visibility has a positive role in promoting microblog marketing conversion rate $\left(Y_{1} \rightarrow Y_{3}\right)$

H3:Microblog marketing interaction has a positive role in promoting microblog marketing conversion $\left(Y_{2} \rightarrow Y_{3}\right)$

H4:Microblog marketing interaction has a positive role in promoting Brand visibility $\left(Y_{2} \rightarrow Y_{1}\right)$

H5:Microblog marketing conversion rate has a positive role in promoting Microblog credibility $\left(Y_{3} \rightarrow X_{2}\right)$

H6:Microblog information quality has a positive role in promoting Brand visibility $\left(X_{1} \rightarrow Y_{1}\right.$ )

H7:Microblog information quality has a positive role in promoting Microblog marketing interaction $\left(X_{1} \rightarrow Y_{2}\right)$

H8:Microblog credibility has a positive role in promoting Microblog marketing interaction $\left(X_{2} \rightarrow Y_{2}\right)$

H9:Microblog credibility has a positive role in promoting Microblog marketing conversion rate $\left(X_{2} \rightarrow Y_{3}\right)$

According these hypotheses, this paper designs the relationship path graph structure between the five latent variables, as shown in figure 1.

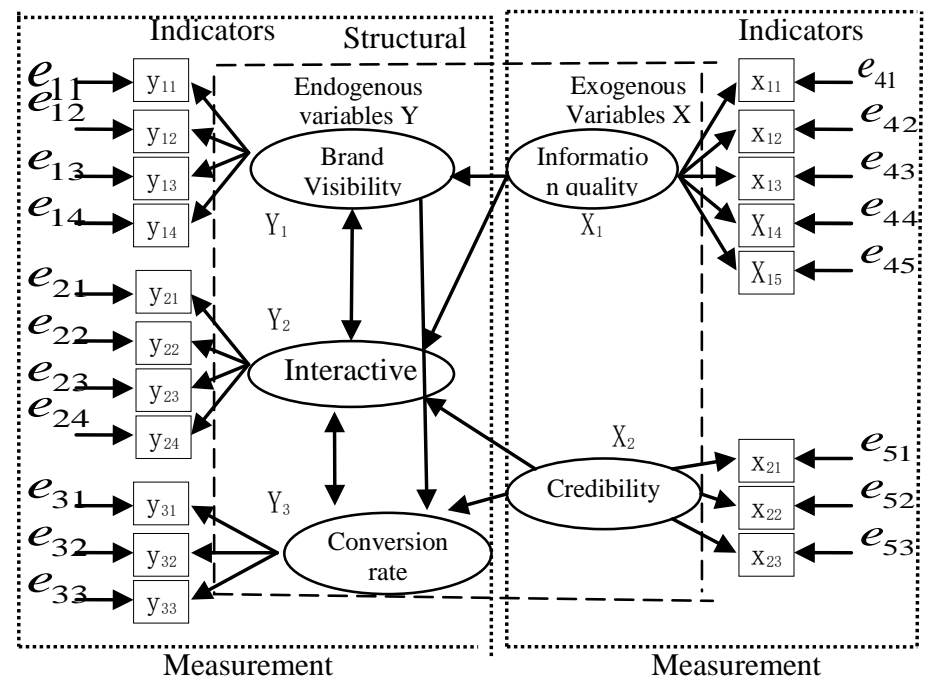

Fig. 1. microblog marketing relationship between effect of path graph structure

\section{EMPIRICAL RESEARCH AND RESULT ANALYSIS}

\section{A. Data sources and processing}

The data mainly comes from sina microblog combining with the characteristics of industry and the peoples' attention, and analyzes skin care products, research range from January 1 2017 to June 1, 2017, a total of 20 weeks, 12 companies, a total of 240 samples, and do normal test and reliability test and validity test to the original data using SPSSv19.0. Cronbach 's Alpha coefficient of total table is 0.886 , the data has a better reliability, indicates that the data is suitable for goodness of fit and path analysis.

\section{B. Empirical result analysis}

This paper analyzes data by AMOSv17.0 software, computing the initial model using the maximum likelihood estimation method. Measuring equation of the parameter estimation results are shown in table 1 after many fitting corrections. The fitting results are good. The remaining eight assumptions have passed the test of significance of different level except the microblog marketing conversion has positive promoting effect of microblog credibility hypothesis.

1) In general, path coefficients standardized of above 0.5 is big effect, 0.3 to 0.5 is the medium effect, and less than 0.3 is little effect. The test results show that brand visibility has different degrees of influence on microblog marketing interaction and microblog conversion rate, path coefficient was 0.42 and 0.42 , respectively, passed the test of significance at the $5 \%$ level, the effects are average. At the same time, also found that the microblog marketing interactive influence on brand visibility has a large degree, the path coefficient was 0.52 , and passed the test of significance of $5 \%$ level, have mutual influence relationship between brand visibility and interactivity, this is actually an "echo effect".

TABLE II. PATH COEFFICIENT TEST RESULTS OF INFLUENCING FACTORS

\begin{tabular}{|c|c|c|c|c|}
\hline $\begin{array}{c}\text { Hypo } \\
\text { thesis }\end{array}$ & $\begin{array}{c}\text { Influence } \\
\text { relation }\end{array}$ & $\begin{array}{c}\text { Path } \\
\text { coefficient }\end{array}$ & $\begin{array}{c}\mathrm{T} \\
\text { statistics }\end{array}$ & $\begin{array}{c}\text { Inspection } \\
\text { result }\end{array}$ \\
\hline H1 & err2 $\rightarrow Y_{2}$ & 0.42 & $1.89 * *$ & pass \\
\hline H2 & $Y_{1} \rightarrow Y_{3}$ & 0.38 & $1.81^{* *}$ & pass \\
\hline H3 & $Y_{2} \rightarrow Y_{3}$ & 0.45 & $3.75^{* * *}$ & pass \\
\hline H4 & $Y_{2} \rightarrow Y_{1}$ & 0.52 & $2.02^{* *}$ & pass \\
\hline H5 & err1 $\rightarrow X_{2}$ & 0.31 & 0.83 & not pass \\
\hline H6 & $X_{1} Y_{1}$ & 0.53 & $2.94 * * *$ & pass \\
\hline H7 & $X_{1 \rightarrow Y_{2}}$ & 0.56 & $2.74 * * *$ & pass \\
\hline H8 & $X_{2} Y_{2}$ & 0.38 & $2.89 * * *$ & pass \\
\hline H9 & $X_{2} \rightarrow Y_{3}$ & 0.41 & $2.78^{* * *}$ & pass \\
\hline
\end{tabular}

2) Microblog marketing interaction also has different degree effects on microblog conversion and brand visibility, path coefficient was 0.45 and 0.45 respectively. It has medium or above influence on the former, and has a great influence on the latter. The influence on the microblog marketing conversion through the test of significance at the $1 \%$ level, the latter is at $5 \%$ level. Interaction affect the change of 
conversion rate through the role of brand visibility, the indirect effect coefficient is 0.2 , the total effect coefficient is 0.65 , belong to one of the important influence factors. The higher frequency the enterprises participates in interaction, the higher activity it has, and the greater influence on fans. It promotes expanding the range of exposure of brand through word of mouth marketing, so make people change their paying close attention to, forward recognition to buying behavior to enterprise products.

3) The conversion rate of microblog marketing influence on credibility failed the test of significance. Possible reason is that is an one-way relationship between the two, and different from the traditional marketing way.

4) In addition, microblog information quality impacts on brand visibility and microblog marketing interactive. The test of microblog credibility for the microblog marketing interaction and microblog marketing conversion are all through significance test at $1 \%$ level, the path coefficient was $0.53,0.56,0.38$ and 0.41 respectively. Information quality has a direct impact on brand visibility, and also has indirect effects impact on brand visibility, coefficient is 0.29 , and the total effect coefficient is 0.82 . Also, on the other hand, it affects interactivity through the indirect role of brand visibility; indirect effect coefficient is 0.22 , the total effect coefficient of 0.78. And has not directly impact on conversion rates, but through the interactive has indirect effect on the conversion rate, effect coefficient of 0.25 .

5) The company credibility has direct effects on the interactive, path coefficient is 0.38 ; It doesn't have directly affect on brand visibility, and just has an effect on brand exposure, path coefficient is 0.2 ; and has a direct effect on marketing conversion, coefficient is about 0.41 . Indirect effect produced by interaction coefficient is 0.17 ; total effect coefficient is 0.58 . Brand credibility is one of the key factors in microblog marketing, if lack of credibility, even if the enterprises do better on other aspects, they can't make people make positive judgment to its content. Therefore, enterprises should pay more attention in establishing brand credibility and influence in microblog marketing gradually.

From the above analysis, the factors playing an important influence on microblog marketing effect are brand visibility, interactivity and three credibility. During these factors, microblog interaction influence to marketing is the largest; the second is microblog credibility and brand visibility. Information quality has an indirectly effect on microblog marketing, but its impact on brand visibility and interactive effects cannot be ignored, at the same time of more interactive, achieved the purpose of improve enterprise microblog marketing effect. Finally, it should be noted that although the eight assumptions are passed significance test, but the path coefficients of load value are generally low, especially the coefficients of brand visibility, microblog credibility to microblog marketing interactive and the conversion are smaller. Microblog marketing campaign has yet to real play the promoting role of brand visibility and microblog credibility to microblog marketing effect in cosmetics industry.

\section{CONCLUSION}

Through above analysis and we get conclusions: the microblog information quality, brand visibility, weibo interactivity and weibo credibility have different degree of influence on microblogging marketing effect. Eight assumptions are passed the degree of significance test, but most of the path coefficient is low. It indicated that the enterprises didn't really use and give play to the role of weibo marketing transformation. Enterprises shouldn't focus on the surface of the microblogging marketing effect, but more focus on maintaining the brand credibility, realize the virtuous circle, and realize the micro blogging marketing integration effect.

\section{AUTHOR IN BRIEF}

XIN Yongrong, Ph D, Associate professor, mainly engaged in network marketing and efficiency analysis..

E-mail: xinyongrong@126.com.

\section{ACKNOWLEDGEMENT}

Sponsored by the philosophy and social science research foundation of Jiangsu province in 2016 (2016SJB880031), the social education program of Jiangsu Province in 2016 (JSS-L2016001),Jiangsu Open University Teaching Reform Research Project In 2016 (16-YB-15),the third batch of top-quality courses in Jiangsu open University2015,Overseas training program for outstanding young and middle-aged teachers and principals in Jiangsu in 2017,Key project of social education plan project of Jiangsu Province in 2017(JSS-B-2017003). Jiangsu university brand professional construction project (PPZY20158195).

\section{REFERENCES}

[1] Sun Jianghua. The influence of social networking features on the marketing effectiveness of micro-blog: An Empirical Study Based on the official micro-blog panel data, [J]. business research, 2017, (2): 12-18. (In Chinese)

[2] Wang Xiaoguang. Study on the influencing factors of micro-blog's marketing effectiveness. Take media micro-blog as an example, [J]. modern information, 2015,35 (7): 57-61. (In Chinese)

[3] Lin Daiying, Kuang Wenjun, when Jundan. Micro-blog movie marketing impact on audience consumption [J]. Youth Press, 2015, (30): 37-38. (In Chinese)

[4] Jin Kun. Micro-blog marketing on consumer purchase intention an empirical research on the influence of $[\mathrm{J}]$. Chinese circulation economy, 2015,29 (12): 37-45.

[5] Liu Tong. Accessible environment and non accessible environment. Analysis of factors affecting micro-blog's marketing [J]. press, 2012, (23): 66-70. (In Chinese)

[6] Xu Caiming. Study on the influencing factors of public participation willingness of micro-blog marketing in China's major sports events [J]. sports and science, 2015, (1): 59-65. (In Chinese)

[7] Brian Halligan, Dharmesh Shah.Get Found in Social Media. Pages[J]: 115-120, 2011

[8] Huang Qiuping. Micro-blog's marketing influence model based on social networks. [J]. management review, 2016,28 (9): 163-171. (In Chinese)

[9] Wang Xia. Study on the influence of brand exposure on online word-ofmouth in enterprise micro-blog marketing [J]. management review, 2013,25 (5): 116-122. (In Chinese) 